\title{
Responsiveness of Driving Curriculum Provision to Efficient Driving Training: Survey into Contemporary Driving Practices in Ethiopia
}

\author{
Endalew Fufa Kufi*
}

* Arsi University, Ethiopia

E-mail: endalewkufi@yahoo.com

\section{Article Info}

Received: October 2, 2021

Revised: November 25, 2021

Accepted: December 15, 2021

\section{$10.46303 /$ repam.2021.5}

\section{How to cite}

Kufi, E. F. (2021). Responsiveness of Driving Curriculum Provision to Efficient Driving Training: Survey into Contemporary Driving Practices in Ethiopia. Research in Educational Policy and Management, 3(2), 22-41.

\section{https://doi.org/10.46303/repam.2021.5}

\section{Copyright license}

This is an Open Access article distributed under the terms of the Creative Commons Attribution 4.0 International license (CC BY 4.0).

\begin{abstract}
This research focused on investigating curricular efficiency in drivers' training to ensure risk-free driving. Issues of concern were efficiency of the driving curriculum with respect to clarity in expected learning outcomes, pedagogic provisions and assessment. Interpretive research design was used to give shape to the data collection and analysis. Data were collected in the form of experiential and archival reflections. Accordingly, experiences in planning, implementing and assessing drivers' training curricula and implementation strategies were looked into. Data were collected from seven institutions providing drivers' training in Asella ( $n=3)$ and Adama $(n=4)$ Towns of Ethiopia, selected through purposive sampling. The findings indicated that, the drivers' training was largely based on a short-span provision which was far below the standard to ensure in-depth practices. The curricular materials lacked wellorganized components with regard to clear statement of learning outcomes, organization of contents and skills, clarity in role-orientation, and depth in assessment. Moreover, the psychological consideration to individual differences among trainees, awareness about would-be customers and coping strategies for risks in time of accidents were less stressed. Though technical aspects of handling vehicles were wellgrounded, awareness about the community with respect to road-safety was minimal. Team-works among concerned stakeholders to boost drivers' understanding and skills were also non-existent.

KEYWORDS

Curriculum; efficiency; risk-free; driving; training
\end{abstract}




\section{INTRODUCTION}

Road transport covers the widest array of services in public communication. For the realization of safe and swift public communication through road transport, drivers' training standard plays an indispensable role. For a standard-based driver training to be realized, due consideration must be given to driving curriculum development, breadth and depth of training provision, assessment of outcomes and improvement of the training strategy.

Several studies have been held around the risk of poor driving on life and property. Yet, in-depth analysis of the curricular, instructional and managerial aspects of drivers' training has not been the point of concern in most researches. Evidence could be traced of a study held by Raftery and Wundersitz (2011) which restricts road-safety issue to school children as vulnerable road-users, the issue of early licensure and the wide-range of promotions media should make to orient people about risks around road-traffic accidents. The research, by far, underscores prospective development of RSE programs to be evidence-based and founded on established principles of best practice both for education and behavior change. The study does not, however, earmark the nature and depth of attention to be given to the training stages.

Topolsek et al. (2019) stress also that, violations of traffic procedures were different among drivers who attended Slovenian Educational programs and those who did not. Yet, the research did not denote the curricular composure and the procedures as core issues.

Coming to Ethiopian context, Abegaz et al. (2014) held a study which dealt with effectiveness of an improved road-safety policy in Ethiopia. The findings indicated that, with the implementation of the recent road-safety policy, the rate of fatalities decreased considerably. However, the implementation of that policy did not have any considerable effect on non-fatal injury. Whereas public awareness campaign, inter-sectoral collaboration, and further improvement using appropriate control device were suggested to support the road-safety policy implementation, little was said about educational intervention to be used.

Dawit (2016), in the research regarding road traffic accident and safety evaluation in the case of Addis Ababa which specifically dealt with Bole Sub-city, analyzed causes of road-traffic accident. The findings reflected certain streets in Bole Sub-city to have been prone to roadtraffic accident due to high traffic volume. The research came up with the proposed breakthrough related with education for pedestrians, drivers and traffic police staff members but did not underline the type and degree of education or training to be used.

Likewise, Abegaz and Gebremedhin (2019), having held research on the magnitude of road-traffic accident-related injuries and fatalities in Ethiopia, discovered high rate of casualty, especially with male young adults and vulnerable road-users. Though "urgent intervention" was said to be in place with consideration of road-traffic accident taken as the foremost public health issue, no attention was given to educational intervention.

Deme (2019) surveying road traffic accident in Ethiopia from 2007 to 2017 revealed growth of road traffic accident from time to time due to factors other than road network coverage and motorized vehicles development. However, the research had little heed on 
educational interventions which could be proactive means of reducing and tackling road-traffic accidents.

The other research was held by Mariam (2014) which investigated road-traffic accident from public health point of emphasis. The researcher underlined drivers' reluctance, pedestrians' lack of awareness, and technical problems to have been spearhead issues for roadtraffic accident but stressed no point about educational breakthrough mechanism.

A study with the head-issue pertaining to traffic accident causes and counter-measures in Addis Ababa to Adama express-way was the other. Road-traffic accidents related to unethical driving (problem with sight distance, phone usage and drug abuse) was the pivotal and major cause (Deme, 2016). The research denoted 402 cases out of 672 to have been related with unethical driving, and only 251 to have been related with technical problems. In that, 19 cases constituting sleeping problems were also underlined. While the study essentially traced behavioral intervention mechanisms to be worked on, it did not earmark what that should bear in specific, especially from road-safety education point of reference.

Tulua et al. (2013) dealt with characteristics of police-reported road-traffic crashes in Ethiopia over a six-years period, and came up with findings that, more than half of the fatalities involved pedestrians and majority of the crashes occurred during day time, which entirely involved males and people in the age range of 18 to 30. From this, it could be clear that, economically active time and people were more likely to face the disaster of road-traffic accident. The research also denoted effective programs to be in place to mitigate the occurrence of the accidents. It also underlined counter measures to be taken to reduce pedestrian crashes but failed to state the comprehensive breakthrough mechanisms to be used as remedial. In the first place, the representational aspect of the research went to subjects prone to accident and time but not causes. In the second, it stated indefinite solutions such as effective programs and counter measures. Stepping on such a research, it would be very hard to seek pragmatic solutions.

Hailemichael at al. (2015) held a study on the magnitude and outcomes of road traffic accidents at hospitals in Wolaita Zone, SNNPR, and found out that, among 384 trauma victims, 240 were reported to have had cases related to road-traffic accidents. The research also uncovered the fact that, majority of those affected $(298,77 \%)$ were males in the age-range of 20 to 29. Like in the study held by Tulua et al. (2013), the prevalence was on those lying in the productive age-group, demographically. With respect to remedial actions to be taken, tailored messages to members of the community regarding knowledge and practices of road-safety measures were gravely stressed. These were also to be arranged on issues of appropriate use of pavements by pedestrians and avoiding risky driving behaviors. The use of safety helmets for motorcyclists was also suggested. Yet, the research did not explicate why pedestrians and drivers did not abide by rules so far, and what educational interventions were to be desirable in a proactive manner. 
Kebede et al. (2019) held a research on road accident-related fatalities in Addis Ababa, which had a special focus on police report, wherein emphasis was placed on accidents and contributing factors. The study revealed that, major causes of road accidents were unsafe crossing of zebra and drivers of commercial cars who fail to give priority to pedestrians. As a remedy, the study recommends pedestrian safety measures and educational interventions to be worked on to bring about behavioral changes. However, it does not unveil the type and extent to which that should go. In brief, the research did not touch the vitality of educational interventions to reduce and curtail hazards related to road-traffic accidents.

Hence, studying curricular efficacy of drivers' training was found to be vital in order to ensure whether curricular, pedagogic/instructional, psychological, ecological and collaborative issues were appropriately addressed in the drivers' training programs overall.

In Ethiopia, driving risks are reported every day, and there are many casualties related to unsafe driving every time. At the back of all accidents, there are causes related to drivers' skill shortage, emotional instability during driving and ecological imbalance. Overall, there are cases leading to accidents which highly pertain to human (driver-pedestrian mismatch), technical (vehicle or highway issue) and ecological (climate or landscape). The vertex for all the issues and cases comes to educational provisions for drivers before they join the driving system. Researches worldwide denote that, even though driving education could be provided for a short span for licensing purpose (Lonero, 2008), there needs to be very broad and in-depth training and education to ensure risk-free driving.

In that regard, Lonero (2008) asserts the following:

Most types of education are considered successful if students meet learning objectives and pass tests, but driver education is expected to change subsequent behavior sufficiently to produce measurable effects on crashes. Driver education has strong face validity among program providers and parents, who think it produces safer drivers.

The above quoted assertion signifies that, programs which meet the demands of passing driving tests may not be sufficient to ensure risk-free driving. So, conditions must be seen to from the standpoint of enabling drivers to experience sufficient changes in behavior (in though and action) such that, their skills can bear tangible effects on crashes and crises management. In that regard, the role of different stakeholders such as parents and training-providers is stated to be paramount for safer driving to be ensured.

Curricular efficiency that would ensure effective and safe driving is a question for all countries of the world which embarks upon technical efficiency, skillful handling of ecological diversity, smooth customer handling and driving safely under stressful conditions and climates. It is evident that, drivers' training takes place based on preset criteria, policy directives and performance strategies. The point however is that, the curricular baseline of driver training is an issue which embarks upon both the cognitive and practical grounds for safe driving. In that 
regard, the extent to which pedagogic, psychological and psychosocial elements are entertained in driver education and training is a case seeking research.

Hence, the focus of this research became efficiency of curricula for driver training, the major issues being curriculum design, pedagogic and psychological provisions, ecological practice- lines and awareness, and involving diverse stakeholders as contributors for drivers' training.

The research dealt with seeking answers for the succeeding questions:

- How far does the curriculum for driver training deal with the didactics of learning and teaching?

- How are drivers' behavioral dispositions taken into consideration?

- How far are technical provisions aligned with the pedagogic and psychological dispositions to ensure customer and environment-friendly driving?

- To what extent do concerned stakeholders participate on drivers' training as the trainees are in the streamline?

\section{Objectives of the Research}

Driver training is a skill-area that helps drivers to be knowledgeable technically and skillfully armed to drive productively and safely. In that regard, research into driving curriculum efficiency is carried out to attain the following:

- To discern the appropriateness of the driving curriculum being used for the driver's safety and productivity, safety of the driving context and the future success of the driving industry;

- To identify the place given for behavioral dispositions both in the curriculum materials and the pedagogic provisions during driver-training in such a way that, drivers can have desirable approaches during driving;

- To ascertain ecological sensitivity and cognizance of driver-training provisions in light of driving under different climatic conditions, highway features, landscape and human-related conditions;

- To earmark inclusiveness of the role of contributive stakeholders such as public health workers, traffic security agents, community administration and transport management officers in the driving context.

\section{Significance of the Research}

This research is expected to contribute the most for the drivers who are trained with different forms of curricula in a sense that, with the materialization of the research findings, they can learn with comprehensive and in-depth curricula.

The research will also be of value to driver training institutions in terms of updating training dimensions in line with the pedagogic, psychological and psycho-social dispositions as well as the technical and ecological points of references in order to have valid and inclusive provisions. 
The research can also provide for the transport management sector from the top line of directives to the bottom in terms of identifying policy-related provisions from practice-oriented curricula. In that, trainees need to learn at curricular level, not policy-orientation, as far as a policy booklet can seldom be used safely and productively as a curriculum material.

\section{Delimitation of the Study}

The scope of this study was delimited in scope to four driver training institutions in Asella Town and three such institutions in Adama City since covering data from all the existing institutions was both unmanageable and costly. Data were also delimited to the current or contemporary practices due to the fact that, up to date data could be more valid and pertinent than older ones. In spite of the need to cover issues related to technical, practical and legal matters, the research highly deals with pedagogic/curricular, psychological, ecological and psycho-social issues.

\section{Research Methodology}

The main issue of the study was to explicate curriculum efficiency in drivers' training from the standpoint of pedagogic, psychological, ecological and stakeholders' collaborative ties. The pedagogic aspects dealt with curriculum planning, implementation strategies and assessment. Likewise, the psychological issues were looked into from the standpoint of personal-social skills which the trainees were deemed to build. Ecological inflections of the training were also investigated as per the need to understand and drive in different climates, highway, community and landscape. The extent to which the drivers-training condition entertained the role of different stakeholders was also a part of the research issues. The inclusion of the aforementioned issues is supported by existing research works such that, greater levels of supervised, real world experience during the learner period reduce post-license crash involvement by up to about thirty-percent. Encouraging cooperation between driving schools and parents in teaching learners how to drive may be beneficial in increasing the quality of instruction, and the quantity of learner driver experience. Moreover, the best learning environment for the beginning driver is the real road system under the supervision of an experienced driver or instructor (Christie, 2001).

\section{Design of the Research}

In carrying out this study, qualitative design of naturalist method was used. The rationale was that, the researcher, while trying to see the situation from the point of view of those studied, was a participant in the investigation and assertion through revitalization and enrichment of data (Frey et al., 1999).

\section{Data Types and Sources}

Data for the study were collected in the form of experiences and document-survey. Experiential data were collected in the form of practices of teaching drivers and institutional holdings. Documentary data were also collected through curriculum material review. Experiential data 
were used with the rationale that, curricular efficiency in drivers-training could not be realized with mere existence of materials, technical assets and trained teachers; rather, with the integration and appropriate use of such resources for safe driving skills to be realized skills to be realized. Driving curricula materials were also reviewed for their pertinence to building appropriate technical, psychological and environmental skills.

\section{Samples and sampling Techniques}

Sample driver-training institutes were selected from those found in Asella Town and Adama City based on purposive sampling technique as per their provisions for public transport driving licensure system. Accordingly, four institutions from Asella Town (Auto, Golden, Rehoboth and Simbo) and three from Adama City (Bekka, Ker-Tek and MM) were taken as core samples as per their provisions. In addition to those institutes, sample TVET institutes and management offices were also contacted to provide data about their roles in supporting driver training institutes.

\section{Procedures of Data Collection and Analysis}

Data for the research were collected through key-informant interview (semi-structured) guide and documentary survey checklist. The interview focused on institutional and official supports based /centered on Pedo-Psychological, Ecological and Collaborative issues. Documentary checklist was used to efficiency of curricular items with respect to intended learning outcomes, contents, roles, resources and assessment techniques. The collected data were carefully categorized and interpreted thematically as per the research questions, based on which summary of major findings were made.

\section{RESULTS AND DISCUSSION}

This part of the research dealt with thematic analysis of qualitative data collected through keyinformant interview and documentary checklist. First, data based in interview was presented and interpreted, and then of checklist.

\section{Efficiency of Curricular Components}

Curriculum components are all elements that make up a certain curriculum with respect to intended learning outcomes, contents, roles and dispositions, technology and assessment techniques or modes. In this regard, the current research dealt with the breadth and depth of structural and pedagogic efficiency of driving-training curriculum. In the interview protocol held with drivers training institutions in Asella Town and Adama City, the participants denoted that, the curricula for training drivers at all levels were first drafted at the Federal Transport Authority offices.

Then, they were cascaded to be used at regional and zonal levels. To signify the assertion, one of the participants had the following to say:

We get the curriculum draft from the regional transport bureau, which, itself, gets

it down from the Federal Transport Authority. The Zone Transport Office makes 
supervision only to follow up whether we are providing training in line with the given standards. (Participant One, Institution-1, December, 2020).

From the quoted assertion about the structural base of the driving curriculum, it could be plain that, there was a top-down arrangement of curriculum design and development through which institutions got things done, and there were seldom cases to have their own means of developing curricula. Another participant had the succeeding assertion to add:

Our training provision follows the directives and standards of the FTA. In that, the authority provides the standards through which all training institutions should work. The resources, techniques and strategies are also arranged based on the standards given from the top offices. An institution which fails to go apace with the given standards is more likely to be deprived of its license (Part-2, Adama, Dec. 2020).

From the two quoted interview accounts, it could be ascertained that, grassroots driving skills provision in the selected sites were dominated by top structuring at the FTA which seldom had the opportunity to provide for or steer the way and the outcomes of the driving practices. Supporting the above notion Lonero (2008) contends that, a beginner driver system should encompass a program theory: theoretical and logical bases of driver education programs; program context: political, administrative, economic, and social environments that influence programs and their effects; program standards: program principles, regulation, and governance; program products and processes: the content and methods of instruction; program organization: structure, operation, and management of programs; and program evaluation: program outcomes, impacts, unintended consequences, and side effects. Driver training, like any other educational activity, has to be based on well-known pedagogical and psychological principles. Sound judgment, developed by the driving instructors and driving examiners over the years is also essential.

The other point of concern was teachers' or trainers' preparations for the best realization of the drivers training. The participants' reflections denoted that, driver trainers were checked as having due educational background in automotive technology field and then driving license. They also indicated that, the trainers were especially checked for having proper pedagogical preparation to provide training, which was held in line with FTA directives as per the set occupational standards. Regarding teachers' preparations, the succeeding reflections were obtained:

Teachers are checked for having three major qualities to be assigned as trainers. First, they need to have a standard-based education, either from TVET colleges or universities in Automotive Technology. Then, they need to obtain standard-based driving license. Third, they need to undergo training and testing that ensures their pertinence in pedagogic skills to provide training. (Part-3, Inst-3, Dec. 2020).

From the set of assertions above, it could be plain that, teachers for driving training were destined to undergo three forms of checkup: subject-mastery, skill-based licensure for personal 
competence and teaching skills competence. But, such constructs as standard-based, training and testing were indicators of the fact that, the driving teachers themselves did not get valid and dependable education as they largely succumbed to training. Moreover, the training institutions were not of the grain that could ensure holistic human resource production and preparation in order to provide driving training. Evidences could be the obtaining of teachers from open market. There were no indicators of on-job inductions and intra-institutional enrichments for teachers so far.

Regarding implementation roles and strategies in driving training, the condition was such that, first the trainees were provided due exposure to the vehicles as per their capacity and interest. Then, technical and psychological lessons were provided.

The technical training provision was based on induction for a considerable time period which dealt with the identification of structural and functional units of a vehicle, as indicated in an interview as under:

The training follows such a procedure. First, we give them a brief orientation on what a vehicle is and how it works in general. Then, we show them the external parts of a vehicle. From that follows induction on the internal parts. The induction also holds identification of individual parcels both externally and internally. (Part. Instructor1, January, 2021)

From the quoted reflection, it could be evidenced that, training provision had the flow such that, general inductions were given first and then specific details followed. The inductions were also provided first externally and then internally. That could be sound pedagogically as it followed the didactics of teaching and learning. Following such didactics would ensure that the instructional procedures could help teachers form a clear image of the learning they want their learners to be able to demonstrate; remind teachers that the success of learning is the most important priority of planning, teaching and assessment; create a clear image of the desired outcome, the starting point of the curriculum, as well as teaching and assessment; and enable teachers to clearly communicate the desired outcome to learners by presenting and explaining the desired outcome to learners as soon as a lesson unit commences and to do so continually (Bulunuz, 2019; Burke O'Connell et al., 2019; Nnebedum et al., 2021; Wyk, 2010).

However, three conditions were manifest to flirt the success of the procedure such being time duration through which the driving induction was provided, teachers' expertise to work efficiently with their students and individual differences among trainees to master key concepts and exercises given in steps. In all the seven institutions referred to so far, the maximum duration was thirty-five days which was divided among the theoretical, technical and practical inductions. Moreover, the driving skill teachers had different levels of qualification, some having Master Degree in the field of automotive technology with competence-based license; others being from TVET institutions. The speed and accuracy levels for trainees to master skills could also be diverse, and seek more commitment and a more considerable time. In the training processes assessed, such conditions appeared to have been bypassed. 
The other pedagogic inflection was assessment mode so far implemented in providing driving training. The custom in training drivers gave emphasis to mechanical aspect more than psychosocial aspect, as indicated in the reflection on the training experiences. One of the TVET instructors in charge of training had the following to say:

Drivers' training involves knowledge and understanding of the vehicle parts at large. In the process, the would-be drivers are required to get hold of skills to drive. For that to be realized, they need to master knowhow and hands-on experiences regarding the structural and functional aspects within the given time period. (PartInstructor-2, Jan. 2021).

This assertion largely emphasizes the physical or mechanical aspect of driving more than social and personal dispositions though there were also assertions underlining the existence of identifying the preliminary apprehensions and skills of candidates in order to help them master the skills.

Though knowledge and understanding were stated to be dealt with in the training process, the domain-specific provision of training was not given any due space. Curricula overall lacked the quality of assessing the trainees' behavior but rather to induce trainees through existing procedures. Most of the assessment was on the technical aspects both at classroom and site levels. One of the participants had to reflect that as under:

The overall assessment is in terms of technical software implementation, theoretical mastery of parcels with their functions, practical assessment and model examination. Overall, these are largely deal with in forty-five days which seem to be very short to ascertain changes in behavioral and practical realms. (Part-Inst-4, Jan. 2021)

The above assertion forwards the curriculum for drivers' training to be new and yet unrevised. That implies the rarity of audit and review on curriculum pertinence. Most of the implementation-related practices also tilt to the technical and mechanical aspects, and the human dimension tends to be less attentive or of minimal concern. Moreover, the time duration within which drivers complete training is only 45 days which is hardly sufficient for trainees to have the required mastery standards. By and large, the driving training appeared to be a one shot phenomenon with rare revisiting or remedial excepting the likely repeating of failed exercises. In spite of the need for drivers to take up-to-date training as a refresher, none of the institutions traced the use of refresher training at all. Such a trend appears to be pervasively apprehensive as it delimits practices as denoted in Lonero (2008, p. 2):

Drivers' training needs to take into account motivation and the target audience's readiness to learn. Such general factors can easily be identified, but content and methods to address them typically have not been put into practice. Driver safety education programs have been more likely to be developed from a common sense perspective than a scientific perspective. 
It is evident from the quoted assertion above that, trainees' readiness and motivation are successively pressing issues which institutions must take into consideration. In that, experiences incorporated into the curriculum in the form of content and methods must also cope with the demand at hand rather than the urge of the business. The hazard is when drivers' education programs are developed based on whims and wishes rather than scientific analysis of the training context and contents.

\section{Regarding Drivers' Behavioral Dispositions}

According to Bucchia et al. (2012), a kind of psychological relationship exists between the driver and the infrastructure in a complex and integrated manner. It is complex as it depends on all those factors referring simultaneously to the driver and the infrastructure surrounded by the environment. It is integrated because the various factors influence and interact with one another. In line with this, the current research forwarded issues of psychological concerns for drivers' training to study, and the subsequent reactions went as under:

Trainees are provided with psychology units accounting for 16 marks. The overall practice is that, the would-be drivers attend a short lesson which prepares them to handle encounters, customers and technical fallouts without frustration. The lessons largely depend on behavioral dispositions required of drivers. (Part-1, Adama, Jan. 2021).

A brief look into the material for psychology lesson showed also that, the material was prepared in both Amharic and Afaan Oromoo. So, it had pertinence to trainees' linguistic background. The objectives largely focused on identification, translation and description of behavior as constitutive outcomes. Yet, the contents were very vast when seen against the objectives and that, there were no exercises, at least case analyses questions, to keep swiftly with behavioral dispositions. Moreover, most of the lesson contents dealt with vehicle features rather than human. Since the portions were left unorganized, largely astray, it was hard to make out what was simple and what was complex. Drivers' behavioral dispositions were not addressed from local or contextual view point as well.

Further assertions on the part of participants denoted also that, there were some means of familiarizing trainees to the practical situation during site training:

Trainees have different dispositions. Some are fast while others are lagging. Some of them have prior exercises with vehicles while others are unfamiliar totally. Some of them come up with frustration. So, we orient them to consider a vehicle to be like any other machine, and their having the capacity and responsibility to handle in the right manner. (Part-4, Asella, Jan. 2021)

The implication, overall, was that, there were early interventions held in order to familiarize the trainees with the driving context. That was very much generic since variety in handling differences was not stated in spite of the existence of various entry-level features. By and large orientation was not sufficient for entry level familiarization since it was very short. 
Cases were also rare for trainees to learn from one another since the instructors took most of the time in prescribing the given contents. The allotted time itself was too short for practices to be elastic.

The other issue was trainees' in-depth understanding of customer handling. Regarding customer-handling training, one of the instructors, perhaps a director, provided the succeeding remark:

We provide training on customer handling, especially how the trainees can deal with people of different emotional dispositions. Since drivers themselves are a part of the community, our conviction is that, they understand how to treat their customers better. Anyway, there is no special training on customer handling thus far. (Part. Instr. 4, Adama, Jan. 2021).

From the above assertion, it could be underlined that, the training on customer handling, as a part of psychological handling was stated to have been given due space but only for a short duration since the trainees were destined to cover the technical and practical portions at large. In addition to the experiential reflection, though the training manuals held different points related to drivers' behavioral qualities, case reports from live situation were not entertained. In that, the driving lessons did not focus on observation-based learning which could enhance the trainees' understanding of good behavior right from what other drivers said or did to customers.

\section{Regarding Ecological Awareness}

The fact that driving is an activity that takes human and natural ecology into consideration necessitated an explicative reflection with respect to climate, landscape, community-based dispositions in road-use safety and the nature of highways. In order to check whether or not the driving training curricula were designed to the standard to arm the would-be drivers with indepth understanding of climate, landscape, community's road-use practices and the nature of highways, analysis was made on some handbooks. For holistic handling of the analysis, a handbook based on Driving in Dangerous Conditions was chosen for its inclusive nature and indepth composure. The book had elaborate presentations that related to driver-environment interplays and related issues. Various driving conditions were addressed in which case night time, rainy days, very hot days and diverse road features were addressed. Care to be taken by drivers were also noted in-depth.

However, the driving handbook on dangerous condition did not have due behavioral objectives, which could direct both the instructors and the practitioners to work towards desirable changes. To that end, the handbook contents were not outlined properly, and were simply given as orders briefing do's and don'ts. Moreover, there were no roles shared between the instructors and the trainees. There were no exercises to activate trainees' role as well. In line with the short period of time allotted to complete the training, lack of outcome and roleindicators as well as lack of due exercises make the provision largely inefficient to be curricular. Well-stated, such materials used in driver-training could serve as supplementary resources. 
However, they cannot qualify to serve as driving curricula materials since they fail to meet the standard of learner-centeredness, practice-orientedness and flexibility. The point to the major goes to calibration of skills that entwines skill mastery with self-assessment. In that regard, Kuiken and Twisk (2001, p. 6) are right to assert that:

[...] the essential issue in safe driving is not so much the development of specific skills, but the ability to balance task demands and skills accurately. Drivers have an ongoing dynamic control over several of the determinants of task difficulty. This balancing of demands and capabilities is also known as calibration.

Kuiken and Twisk (2001) earmark also that, correct calibration of the driving-task and coping abilities largely depend on the degree of practice and the amount and quality of working feedback that a driver receives. It is suggested that driver training should incorporate techniques to match self-assessed ability to actual ability. In that, drivers should learn to actively search for, and use, the feedback that the driving environment provides them with.

With respect to depth of practices to enable drivers work across different land features, the instructors had the succeeding assertion:

Site-based practices begin with passing through brakes, which require trainees to move forward and backwards thereby controlling the vehicle when driving in a tight situation where other vehicles may be crossing or coming nearer from behind. Such a practice also helps trainees to regulate their speed and move with care retaining the right direction and distance. (Part. Inst. 3, Asella, Jan. 2021).

From the assertion set above, it could be seen that, site-based training was partly simulating scene since it involved practicing with an authentic vehicle in a seemingly environment in the first instance. In a curricular dimension, such a practice is sound enough to bring would-be drivers some insights of handling vehicles while driving. However, the amount of practice and the human relationship between trainees and trainers was something left to question since physical ability or inability to succeed in handling vehicles could be an indulging or frustrating scene which could bear dwindling situation to the former. Haste to make decisions on the part of trainers could also suck strength of the training skill out of life.

Another point of concern was the exposure trainees had to practice across different landscapes such as steeply and sloppy features, junctures and twisted lanes. One of the participants had the following to reflect:

After covering most of the training portions, trainees are taken out to the field for field practice. Perhaps, this is an on-campus and off-campus practice at large. The practice lesson is partly done in the field and partly in the classroom. The field practice involves going through different topographic features and road setups where different vehicles move. However, the season does not allow practices under different weather conditions and taking any farther move to different topographic features. (Part. Instr. 3, Asella, Jan. 2021). 
Though relatively good to have site-based training with due supervision from trainers, and in spite of the breadth of provision on and off-campus by diversifying the time, lack of opportunity for in-depth training under different climatic conditions and topographic features may have striking effects on the overall skills and fluency with which drivers could be armed. Drivers never live working under the same condition they experience during practice; they encounter different climatic and topographic features for which they need deep exposure during training.

\section{Practices of Working with Key Stakeholders}

The fact that driving training takes account of the support from different stakeholders necessitated looking into the likely participation of some proximate agencies in providing due supports for institutions. Hence, institutions were asked to brief whether they had broad ties with traffic security agents, road transport officers, health officers and community leaders. The point was that, in most cases traffic police agents worked on regulating the materialization of driving rules and regulations to the extent of levying penalty. Yet, their provision for initial training was not considerable.

Road transport agents also deal with checking the standard to which trainings were provided by respective institutions yet with minimal roles in training interventions. When accidents came about, health officers were read presenting the backwash effects as far as research reports yet their cautionary input for driver training was not marked well. Having community-driven crisis in road safety problems is common in Ethiopia where people use roadside businesses or get prone to road accident as pedestrians either due to their own defects or the drivers' misdeeds. Yet, the role of community-leadership in drivers' training situations was not considerably marked. It was, then, from that inclusive demand for stakeholders' training inputs that, the research looked into the driving institutions' experiences where the succeeding remarks were provided:

There are different interest groups which come to our institution. Their role is in making occasional follow-up in the form of surprise visits and on-going feedback. That does not embrace any training input. Rather, it begets feedback in the form of corrective action required of the institution. (Part. Director-1, Asella, Jan. 2021).

Three points need attention here. In the first place, there were many interest groups which had but a few roles in providing for training activation. The second point was that, even those which came for visit dealt with corrective remarks which hung at institutional level; not went to the trainees. The third point was in the limitedness of the feedback provision in time and coverage. That means, the feedback provided did not have long range of coverage.

Another assertion of importance to the research also had the following to bring forth regarding stakeholders' training -based inputs:

Traffic police officers, transport management officers and other concerned centers must have had deep roles in providing for drivers' training. Yet, such a practice is 
not developed at a workable standard, even non-existent. That could be due to lack of awareness and working ties with such offices on the part of the institutions and the offices themselves, excepting follow-ups and regulatory actions in the aftermath. (Part. Director-2, Adama, Jan. 2021)

The above assertion notes that, there was necessity to have in-depth provision on the part of key stakeholders such as traffic security offices and transport offices both for legal and technical supports. However, such supports were not institutionally planned. They were not officially schemed either. So, the gap was manifest both on the part of the institutions and the offices.

In relation to that, driving institutions were also asked if or not they had interinstitutional exchanges of experiences and symposia to accentuate their practices on mutual bases, to which the succeeding remark was given:

Driving institutions work independently cut off from other institutions. Experiential exchange is not framed at any curricular or co-curricular standard. The leading offices also have little contributions in devising and following up such mutual exchanges. This is without denying the necessity to have experiential sharing and exchange. (Part-Direct-3, Asella, Jan. 2021).

From the quoted reaction, it could be inferred that, institutions did not have planned means of exchanging experiences on drivers' training. The point was also that, both curricular and co-curricular handlings were held at individual institutional contexts, and there existed a highly competitive rather than cooperative atmosphere.

Another reaction given a TVET instructor overseeing institutional training provision indicated that, the institutions providing training tilted towards fast business-making rather than strengthening the training bases through experiential exchange and discussion with other related stakeholders. Evidences are stated as under:

I frequently go to the training institutions both to see to curricula and instructional processes. I seldom see institutions coming together to enrich their holistic practices. Since the business season is fast-routing and competitive, they highly tilt to catching up with that opportunity. (Parti-Instructor 2, Asella, Jan. 2021).

The above response account denoted absence of cooperative atmosphere among drivers-training institutions owing to the high demand for financial benefit, and less attention given to improving the training process and implementation system through exchange of experiences. The overarching points are that, both driving institutions and leading offices fall short of skills and initiatives to use means of networking experiences in order to foster better and risk-free driving on the basis of experiential exchange. 


\section{SUMMARY OF MAJOR FINDINGS, CONCLUSIONS AND RECOMMENDATIONS}

On the basis of experiential explication and analysis made on efficiency of driving curriculum, the succeeding findings were made out.

\section{Summary of Major Findings}

\section{Regarding Curriculum Design and Pedagogic Efficiency}

With respect to curriculum design, the findings denoted that, essential components (Objectives, contents, teaching-learning roles, and supportive technology and assessment modes) were not administered properly. Some of the materials were presented in the form of copies of bookchapters rather than training manuals which appeared to be below standard to be considered sound and workable.

Even where curriculum components were set, there was a great mismatch observed between objectives of the training courses and the underlying components stated for complementary purpose. In that, there were more contents than objectives. Teaching-learning roles were not addressed at all. The supportive technology resources were not stated for each lesson though the practice dictated the use of models, pictures and audio-visual supports in order to boost skill-based engagement.

With respect to pedagogic provisions, linear means of lesson-delivery was observed in all the concerned institutions. Lecture and demonstration methods were employed at large. Moreover, practice sessions were very short such that, they were not sufficiently set to held curb gaps in training provision through formative and diagnostic supports. In the real sense of making the training situation active and provide for trainees' self-regulatory practices, the pedagogic or curriculum implementation procedures must have designed and made to practice on participative, formative and developmental manner of the trade. Participative learning in the form of flipped classroom could help much in that regard as it could provide for students' practices of technology well-ahead, increased engagement and progressive communication between the trainees and the trainers (Albalawi, 2018; Alharthi \& Zhang, 2021; Çakır, Sayın, \& Bektaş, 2021; Fayombo, 2012; Murat \& Cam, 2021; Okmen \& Kilic, 2020; Shukla \& Mcinnis, 2021; Stone, 2012).

\section{Regarding Psychological Skill Efficiency}

Would-be drivers in training institutions are destined to undergo psychological training in-depth for smooth communication and crisis management (Bucchia et al., 2012). In the context of this research, there was some kind of course-based provision which bore psychology contents pertaining to drivers' behaviors, vehicle features and overall cares to be taken before, during and after driving. Remarkable were pivots pertaining to driver behaviors warning against use of alcohols or other substances which might trigger emotional uplift. The manuals also warned against speedy driving and unchecked starts and parking. However, excepting cautionary provisions, the psychology lessons did not give authentically-present risky situations relating to the backwash effects of unsafe driving and models of careful driving, as exemplary resources. 
Cases related to handling crises during inevitable accidents were not stressed much still. Trajectories of heavy music sounds, disturbing debates and orders from other bodies which might harm both the driver and customers were not taken to view either.

With respect to efficiency of curricular components in the psychology module for drivers' training, there were very few objectives which highly represented lower level cognitive skills (knowing, understanding and demonstrating). Even those objectives referred to identifying meanings of terms and procedures rather than pointing out systems and operations in driving ( $r=0.64)$. Moreover, there were contents which rarely represented the expected outcomes or intents to be met. For instance, most of the contents represented analysis and synthesis level intents which were not sufficiently stated in the predetermined objectives $(r=0.73)$. Though there were notations and designs to direct the trainees towards analysis and synthesis in learning ( $r=0.67)$, teaching and learning roles were not clearly stated $(r=0.84)$.

\section{Regarding Contextual /Ecological Efficiency of Drivers' Training}

Besides providing for driver-vehicle-customer relationship, drivers' training must arm trainees with environmental awareness and skills. In this research, three ecological components were taken into consideration: Physical ecology, pertaining to road feature and climate, human ecology, pertaining to community road-use practices and use, and durational. Both the training modules and experiential explications denoted more emphasis to have been given to the physical ecology and seasonal ones as in driving through too hot or too cold weather situations. Durational ecology was also addressed in terms of driving during nights and rainy seasons. However, formative means adapting trainees to the different ecological situations were not considered owing to time factor. The human context pertaining to safe road-use practices was not given much attention, especially with respect to handling pedestrians, taking care of roadside business makers and people sharing roads under pressure of drinks or worries.

\section{Regarding Communicational and Collaborative Efficiency of Driving Curricula}

The drivers' training situation is surrounded by different stakeholders deemed essential to share roles. In that regard, proximately acting transport and road-traffic security agents, health officers and community administration centers were the major stakeholders taken into consideration. The addressed drivers' training institutions had some roles with transport management offices which pertained to supervisory and steering supports but no training supports. Likewise, the institutions were found to have had no training-based roles to share with traffic-security and health offices at large. So, communicational and collaborative efficiency of the driving curricula was minimal as it depended on the office-to- office communication in a top-down fashion.

\section{Conclusions}

Based on the summary of findings above, it could be ascertained that, the driving curriculum set for institutions in the research context had more technical efficiency in terms of driver-vehicle relationship but less efficiency in driver-environment and driver-community aspects. Since trainings were provided within a short period using very few technical and spatial resources, the 
efficiency of the driving curriculum to ensure cost-effective skill obtaining was found to be shallower.

The curriculum materials were not armed with the necessary components which could ensure completeness and depth. Model behaviors in terms of driving safety and crises management were not employed as exemplary resources to which effect self-regulatory situation was less practical. Ecological awareness and skills were also delimited to given practice sites, and that, the driving training situation depended more on cognitive sets rather than practice-based induction.

Little contributions were also observed on the part of stakeholders where only bureaucratic steering ties were manifest. Therefore, the succeeding recommendations were given in order to make the driving curriculum better and contextually productive:

\section{Recommendations}

Cognizant of the shortage in curriculum components, there is acute need for revising the drivers' training manuals for completeness and depth. So, the transport management offices at respective levels need to organize curricula in a standard format as to enclose all the essential components with didactic concerns taken afoot.

The institutions providing driving training need to devise curricula and driving practices need to deal with contextually rich behavioral inputs which could make would-be drivers aware of the likely causes of accidents related to misbehavior as well as technical, ecological and collaborative breakthrough. Further research is also sought essential on how to make efficient use of experiential resources from road-accident data which could enrich the driving training system on contextual bases, and experiential models inland.

\section{REFERENCES}

Abegaz, T., \& Gebremedhin, S. (2019). Magnitude of road traffic accident related injuries and fatalities in Ethiopia. PLOS ONE, 14(1), e0202240. https://doi.org/10.1371/journal.pone.0202240

Abegaz, T., Berhane, Y., Worku, A. \& Asrat, A. (2014). Effectiveness of an improved road safety policy in Ethiopia: An interrupted time series study. BMC Public Health, 14(539). https://doi.org/10.1186/1471-2458-14-539

Albalawi, A.S. (2018). The effect of using flipped classroom in teaching calculus on students" achievement at University of Tabuk. International Journal of Research in Education and Science (IJRES), 4(1), 198-207. DOI:10.21890/ijres.383137

Alharthi, M. \& Zhang, K. (2021). Faculty's Use of Social Media in Flipped Classrooms: A MixedMethod Investigation. International Journal of Technology in Education and Science (IJTES), 5(3), 394-410. https://doi.org/10.46328/ijtes.232

Bucchia, A., Sangiorgi , C. \& Vignalia, Va. (2012). Traffic Psychology and Driver Behavior. Procedia - Social and Behavioral Sciences, 53, 973-980 
Bulunuz, N. (2019). Introduction and Assessment of a Formative Assessment Strategy Applied in Middle School Science Classes: Annotated Student Drawings. International Journal of Education in Mathematics, Science and Technology (IJEMST), 7(2), 186-196.

Burke O'Connell, N., Dempsey, M., \& O'Shea, A. (2019). An Investigation of Students' Attitudes to Science, Mathematics and the Use of Technology in Lower Secondary Education. International Journal of Education in Mathematics, Science and Technology (IJEMST), 7(4), 319-334.

Çakır, R., Sayın, V., \& Bektaş, S. (2021). Bibliometric Analysis of Studies Conducted between 2015-2019 on the Flipped Classroom Model. International Journal of Research in Education and Science (IJRES), 7(1), 163-187. https://doi.org/10.46328/ijres.1126

Christie, R. (2001). The Effectiveness of Driver training as a Road Safety Measure: A review of the literature. 2001 Road Safety, Research, Policing and Education Conference, Melbourne, Victoria, 18-20 November 2001, Monash University.

Deme, D. (2016). Traffic accident causes and counter measures in Addis Ababa-Adama Express Way. [M. Sc. Thesis], Addis Ababa University.

Deme, D. (2019). Road Traffic Accident in Ethiopia from 2007/08-2017/18. American International Journal of Sciences and Engineering Research, 2(2), 49-59

Fayombo, Grace A. (2012). Active learning strategies and student learning outcomes among some university students in Barbados. Journal of Educational and Social Research, 2(9), 79-90.

Frey, L., Botan, C., \& Kreps, G. (1999). Investigating communication: An introduction to research methods (2nd ed.) Boston: Allyn \& Bacon.

Hailemichael, F., Suleiman, M. \& Pauolos, W. Magnitude and outcomes of road traffic accidents at Hospitals in Wolaita Zone, SNNPR, Ethiopia. BMC Research Notes 8(135), https://doi.org/10.1186/s13104-015-1094-z

Kebede, A. Beyene, T. \& Geremew, H. (2019). Road accident-related fatalities in Addis Ababa City, Addis Ababa, Ethiopia. An analysis of police report 2013/2014. https://ecromicon.com/ecec/pdf/ECEC-03-00053.pdf.

Kuiken, M.\& Twisk, D. (2001). Safe Driving and the Training of Calibration: Literature Review. https://www.swov.nl/sites/default/files/publicaties/rapport/r-2001-29.pdf

Lonero, P. L. (2008). Trends in Driver Education and Training. American Journal of Preventive Medicine, 35(3 Suppl), S316-23.

Mariam, D. H. (2014). Road Traffic Accident: A major public health problem in Ethiopia. Ethiopian Journal of Health Development, 28(1), 1-2.

Murat, M. \& Cam, A. (2021). Flipped Classroom on Fifth Grades' 21st Century Skills and Scientific Epistemological Beliefs. International Journal of Technology in Education (IJTE), 4(4), 752771. https://doi.org/10.46328/ijte.94

Nnebedum, C., Obuegbe, A. S., \& Nwafor, H. E. (2021). Assessment of Schools' Reopening after COVID-19 Closures. International Journal on Studies in Education (IJonSE), 3(2), 86-91. 
Okmen, B. \& Kilic, A. (2020). The Effect of Layered Flipped Learning Model on Students' Attitudes and Self-Regulation Skills. International Journal of Research in Education and Science (IJRES), 6(3), 409-426.

Raftery, S.J. \& Wundersitz, L.N. (2011). The efficacy of road safety in schools : A review of current approaches. Centre for Automotive Safety Research.

Shukla, N. J., \& Mcinnis, E. (2021). Flipped Classroom: Success with First Year Mathematics Students. International Journal on Social and Education Sciences (IJonSES), 3(1), 32-47. https://doi.org/10.46328/ijonses.56

Stone, B. B. (2012). Flip Your Classroom to Increase Active Learning and Student Engagement. https://cn.polyvision.com/24/ moodle ruhr-unibochum de/m/pluginfile.php/278895/mod resource/content $/ 3 /$ ICM Effects\%20of\%2 OActive\%20learning\%20strategies\%20and\%20student\%20feedback.pdf

Topolsek, D., Babic, Dario, \& Flolic, Mario. (2019). The effect of road-safety education on the relationship between drivers' errors, violations and accidents: Slovenian Case Study. European Transport Research Review. 11(18). https://doi.org/10.1186/s12544-0190351-y

Tulua, G. S., Washington, S., \& King, M. J. (2013). Characteristics of police-reported road traffic crashes in Ethiopia over a six-year period. Proceedings of the 2013 Australasian Road Safety Research, Policing \& Education Conference 28th - 30th August, Brisbane, Queensland. http://163.44.197.34/theses/t02en.pdf

Wyk, M. M. (2019). The Selection of Didactic Principles by Teachers in the Field of Economics: An Exploratory Factor Analysis. Journal of Social Sciences, 24(2), 111-119. 